\title{
Investigating the Relationship between Lifestyle and Religiosity: A Case Study
}

\author{
Jahangir Jahangiri, ${ }^{1, *}$, Sedighe Jahanbazian ${ }^{2} \&$ Sadegh Panahinasab $^{1}$ \\ ${ }^{1}$ Department of Sociology and Social Planning, Faculty of Social Sciences, Shiraz University, Fars, Iran \\ ${ }^{2}$ Tarbiat Modarres University, Tehran, Iran \\ *Correspondence: Department of Sociology and Social Planning, Faculty of Social Sciences, Shiraz University, Iran. \\ Tel: 98-917-118-4112. E-mail: jjahangiri@gmail.com
}

Received: March 26, 2016 Accepted: April 14, $2016 \quad$ Online Published: May 8, 2016

doi:10.5430/sass.v3n2p1 URL: http://dx.doi.org/10.5430/sass.v3n2p1

\begin{abstract}
In the modern society the viewpoint of the young generation toward religion, especially students, has changed in comparison to that of the past generation. The young generation is in search of a new identity and status which is in contrast to that of the previous generation. In this work, the relationship between lifestyle and religiosity of dormitory students of Shiraz University has been studied through survey method and by means of questionnaire. The sample size is 325 students. The theoretical structure is based on Gluck and Stark model. To measure religiosity, the affective, consequential, belief and ritual dimensions have been taken into account. Based on these, seven hypotheses were proposed. The variables of parents' education, affective, consequential, belief and ritual dimensions have a significant relationship with lifestyle; however some variables such as age, ethnicity and the ethical dimension of religiosity in relation to lifestyle these hypotheses were rejected.
\end{abstract}

Keywords: religiosity; lifestyle; university students; case study

\section{Introduction}

After the Islamic Revolution in Iran and the promotion of religious intellectuals to the top of the political power pyramid, effort to establish the governance of Islam in all aspects of the society was launched as a basic and pivotal ideal. Nowadays in scientific societies, the society of Iran is recognized as a religious one and almost all social studies done to measure Iranians' religiosity confirm this statement. Entering the new era and consequently the loss of religious beliefs and values in modern societies and industrialization and technology development have led to the impeachment of knowledge, values, traditions, ethical and religious ethics and rituals. In these conditions people need identity (Iman and Keizaghan 2002). Erikson as the first important theoretician of identity defines it as a relatively stable sense of unity. Besides this he says: the feeling "who we are?" should be in line with the attitude others have about us, this shows the significance of the relationship between individual and society in Erikson's theory. Identity is divided into individual and social levels. Social identity is a kind of self-knowledge in relation to others. One of the aspects of social identity is religious identity (Khajenoori et al, 2012). Religious identity refers to the relationship between man and religion and the attribution which man finds in this connection. The cornerstone of religious identity is obligation and commitment (Rafatjah and Shakoori, 2008). Religion is the cornerstone of religious order and is a source for social values and affects individual choices and many other aspects of routine life and also is considered as the crystallization of the collective spirit and a reason for the unity and integration of the society. Nowadays phenomena like rural migration, the emergence of different media, developed educational system and so on have impeached values and traditional relations and have caused changes in the religiosity of the new generation, and researchers have to deal with those factors influencing the religious beliefs of the young generation on one hand, and proposing solutions for overcoming this crisis on the other hand. Theoretical analyses show that in societies in transition, religiosity is one of those variables which, has undergone extensive changes. Religiosity in Iranian society is not an exception concerning these changes. Peter Berger for the first time follows these changes in the most important carriers of modernity (economics, industry, government...), and university which has the function of producing science and technology in the society, to Berger, is one of the important carriers of modernity. Therefore 
students can be considered as one of the carriers of modern knowledge in developing countries.

The modern Iranian generations are under the influence of the religious culture of their own society on one hand, a culture which is respected by the family and local communities, and they are influenced by educational institutions, social media (domestic and foreign) and the elements of the modern world on the other hand. Also the young generation has been suffering from some social and economic problems which are due to certain instabilities before and after the war (Serajzadeh, 2005:190). In the modern society the viewpoint of the young generation on religion has changed drastically in comparison to that of the previous. In such a society the young generation is in search of a new identity and status which is in contrast to the mentality and approaches of the previous generation. The main actors of social movements in recent decades in the Iranian society are those young men and women who have reacted against the traditional mentality. Every change in a society through the process of transition from tradition to modernity leads to some movements among the young generation, in a way that one can talk about youth special culture. Religion exists in every culture in various forms and usually plays the main role in individuals' life. Different definitions have been proposed for religion.

Freud believed that religion is the most complex phenomenon in the human civilization and it cannot be explained by referring to just one factor. William James defines religion as those feelings, actions and experiences of the individual in relation to what he/she takes to be divine. For Proser, religion is a set of serious beliefs, behaviors, feelings and attitudes (Aryan, 1999).

Concerning the role of religion and religiosity in social contexts, choosing the concept of lifestyle seems appropriate. Because this concept includes components such as consumption patterns and leisure activities, the element of choice has a pivotal role in them, and Islam contains ethical maxims, rituals and instructions and norms that can limit or create opportunities in fields such as leisure and consumption (Berger and et al, 2008: 98).

For Giddens, lifestyle is a comprehensive set of performances which are undertaken by the individual because they not only help him overcome his current needs, but also conceptualize a certain narrative which he has made for himself against others (Giddens, 1999: 120). One of the consequences of modernity and globalization is the choice of lifestyles, and as Giddens expresses these choices do not lie within the domain of traditional institutions. The most important traditional institution is religion. According to human life history it can be observed that religion in the past had various functions and roles and undertaken different responsibilities in human life. With the emergence of modern institutions, however, some of these functions were delegated to other institutions and commitment to religion has undergone drastic change. Lifestyle includes different consumption patterns, leisure time, ways of interaction and even the latent cultural developments in a society.

Therefore due to the importance of lifestyle in the modern society, paying attention to this concept in the Iranian society is of vital importance, because the Iranian society is on the verge of modernity and is facing many features of modern lifestyle including consumption, wearing, makeup, the importance of body, leisure, joy and so on. According to Bourdieu just economic factors cannot determine individuals' lifestyles, but other sources such as cultural, social, religious, and symbolic capitals are effective on the action and lifestyle of men (Storey, 2007). Therefore religion as one of the main sources of society helps people to distinguish themselves by their attitudes, behaviors and finally their lifestyle. Since the Iranian society is a religious one, religion as a capital has a striking influence on the action and lifestyle choices and the material as well as cultural consumption of the individuals. One should bear in mind, however, that facing modernity and its components including rationalism, individualism, consumerism, and... is followed by changes in all economic, social and cultural fields as well as in the religious beliefs.

These issues are so important that the main focus of religion sociology studies from the very beginning has been the modern society and the important developments occurring in the field of religion (Williams, 2007:2). Therefore, in the present study dormitory students' lifestyles, which have been exposed to modernity and also grown up in a religious society, are highlighted. This study wants to show how the lifestyle of religious students and those with less religiosity are directed, in other words, how religious commitment has influenced their lifestyle, or which components of modernity have influenced them, and finally how much their lifestyles have been influenced by the coexistence of tradition and modernity.

\section{A Review of Previous Researches}

Karami Ghahi and Zadsar (2013) conducted a research entitled "The Relationship between Religiosity and Lifestyle in Tehran". The statistical society includes women above 20 in Tehran and the sample size was 361 , which was determined through multi-stage cluster sampling. The regression analysis showed that out of the independent 
variables of the study- religiosity and age- have a weak correlation with the dependent variable. The highest correlation between religiosity and way of life $(\mathrm{r}=/ 162)$ was approved. Also hypotheses of the relationship between women's lifestyle, body management and consumption norms were approved. The most important achievement of the present study is related to the relationship between religiosity and individuals' lifestyles. Based on the results, religion being most explained, was in the field of consumption patterns $(r=/ 247)$ which was not a striking figure. Also the results can be explained based on the emergence of different religions, the emergence of various and individual forms of religiosity is one of those fields which reflects the formlessness of the modern era.

Khajenoori and et al (2012) conducted a research entitled "The Relationship between Religiosity and Lifestyle among the Young Men in Shiraz". To test the hypotheses of the study 560 young men between 15 and 29 years old were chosen through multi-stage random sampling. The methodology of the research was survey method and was conducted by researcher-made questionnaire. The obtained results at the bivariate analyses have shown that the variables of gender, the respondent's and his father's income, the respondent's and his father's education, the new style of leisure time, the new use of information and communication technologies, religious style and finally the style of body management are in correlation with the religiosity of the young men. Also the results of multivariate analysis shows that religious style, virtual networks, using foreign media, body management and finally the new information and communication technology and cultural style totally have explained 32 percent of the dependent variable changes.

Zolfaghari and Nosrati (2012) conducted a research entitled "The Effect of Religiosity on the Lifestyle of Young Men in Tehran". The statistical society of this study was the young men between 18-29 in the upper and lower areas of Tehran, and the sample size was 294 people. Through survey method these lifestyles have been dealt with in a comparative study, and finally after recognizing the types of traditional, modern and combined lifestyles, their relationship with the religiosity of the young men were measured. The results of the study show that the less religious individuals are, the more their lifestyle is modern, and the more they are religious, the more traditional and non-modern their lifestyles would be. Also among the main components of lifestyle recognized in this study, body management and paying attention to fashion as the young men consumerism, were more influenced by modernity in comparison to the other ones and have been modernized.

Salmoirago-Blotcher et al (2011) conducted a research entitled " Religion and Healthy Lifestyle Behaviors among postmenopausal Women". Possibly religion propagates a healthier lifestyle. The sample size was 71689 postmenopausal women without any chronic diseases who took part in the observational research "Women's Health Initiative". Healthy behaviors were studied by means of logistic regression. After setting the complicating factors, attending prayers had a positive relationship with using preventive services. These findings show that attending prayers has got a relationship with some healthy behaviors.

Gillum and Holt (2010) conducted a research entitled "The Relationship between Religious Participation and HIV Behavioral Risk Factors in American men and Women in a National Health Survey". AIDS which occurs because of $\mathrm{HIV}$ is one of the main causes of death. This hypothesis was tested whether each component of the religious variable has an inverse relationship with the spread of AIDS or HIV factors risk or not. A national survey including 9837 people between 15 to 44 with complete data about religious conflict, sexual behaviors, and drug abuse was conducted. The possibility of women, who never attended prayers, to report HIV factors risk was twice those who attended prayers once or more in a week. Main Line Protestants were less likely to report factors risk in comparison to those who didn't have any attachment. No independent and significant relationship concerning the importance of religion was found. Women who attended public religious prayers were less exposed to HIV factors risk.

Ellison and et al (2010) conducted a research entitled "Religious Sources, Spiritual Contentions and Mental Health in a National Case of US Church Priests". An increasing number of studies are being done on the patterns and signs of spiritual health among priests and those specialized in the field of religion. The study distinguishes between religious sources (support from church members, the positive ways of religious encounter) and spiritual contentions (disturbed relations with God, negative interactions with members, chronic religious doubts). Religious sources predict welfare in a stronger way, while spiritual contentions have a closer connection to psychological disorder.

\section{Theoretical Framework}

A considerable number of studies have approved the direct relationship between religiosity and physical and psychological health, however, the question here is that what is exactly meant by religion and how religion can have such effects? To answer this question first a definition of religion should be provided. To give an operational definition of religion and religiosity has been always a difficult and controversial task. In this study religion has been 
defined as the degree of respect and interest that the person has toward religion. The important point concerning religion is one-dimensionality or multi-dimensionality. Gluck and Stark's studies are on these grounds. Charles Gluck tried to understand and delineate religion between 1950s-60s. He revitalized the discussion of religious commitment dimensions in the country and by Radney Stark's cooperation proposed a new model of religious people in 1956. Their main objective was to understand the different ways by recourse to which, think of themselves as religious.

Gluck and Stark believed that though religions differ from each other in some details, but have general fields through which they are crystallized. They have proposed four main dimensions as the general and obligatory dimensions of religion: practice, belief, experience and knowledge.

Gluck and Stark's model of religiosity is one the first models of religiosity from which other models have borrowed their dimensions. The recent studies show that scholars in the field of religion are inclined toward the multi-dimensionality of religion. Gluck and Stark's model has been relatively used or completely used and followed in most studies on religiosity. Based on this model, in all religion, despite differences in details, there are many common grounds. These dimensions include belief, experience, consequence and ritual and intellect.

The belief dimension or religious beliefs refers to those beliefs which followers of a religion are supposed to believe in and follow. The experiential dimension or religious feelings refers to emotions, images and feelings related to the relationship with God or the ultimate reality. The ritual dimension or religious practices include the prayers and those practices as emphasized by religion. The intellectual dimension or knowledge includes those basic information and knowledge underlying the beliefs of a religion that followers are expected to know.

Consequential dimension or religious effects, refers to the reflection of the four mentioned dimensions in the routine life of the followers (Serajzadeh, 2005). Therefore the objective of this work is to study the relationship between the belief, experiential, consequential and ritual dimensions with the four dimensions of lifestyle, economic capital, cultural capital, social capital and symbolic capital. In other words, the objective of this study is to determine which dimension of religiosity is related to lifestyle. The reason that Gluck and Stark's model has been used here to measure the dimensions of religiosity is that this model is highly valued in the literature of religion sociology and attracts the attention of every researcher and scholar in the field of religion in the first searches. Besides these, the capacities of this model and its simplicity and affinity to Islamic teachings can be other justifications for using this model.

\section{Method}

The study is based on survey method and the tool for gathering data has been questionnaire. To determine the validity and reliability of the questions, face validity and Cronbach's alpha technique were used respectively. The statistical society of the study included the male dormitory students of Shiraz University. Based on Cochran formula the sample size is 325 . In this study religiosity has been considered as the independent variable and lifestyle as the dependent one. What is meant by religiosity in this study is the obligation of the individual to Islam in all its different aspects (Serajzadeh, 2005).

Alpha obtained for the religiosity variable was $87 \%$. Lifestyle, as mentioned in the theoretical discussions, includes a set of attitudes, values, ways of behavior and individuals' interests. Cronbach's alpha for lifestyle was 79\%.

\section{Hypotheses}

There is a significant relationship between age and lifestyle.

There is a significant relationship between parents' education and lifestyle.

There is a significant relationship between ethnicity and lifestyle.

There is a significant relationship between the belief dimension of religiosity and lifestyle.

There is a significant relationship between consequential dimension of religiosity and lifestyle.

There is a significant relationship between the ritual dimension of religiosity and lifestyle.

There is a significant relationship between religiosity and lifestyle. 
Table 1. Cronbach's Alpha of the Independent Variable and Its Dimension

\begin{tabular}{ccc}
\hline $\begin{array}{c}\text { Independent } \\
\text { Variable }\end{array}$ & $\begin{array}{c}\text { Cronbach's alpha } \\
\text { coefficient }\end{array}$ & $\begin{array}{c}\text { The Number } \\
\text { of Items }\end{array}$ \\
\hline Religiosity & 0.87 & 27 \\
Belief & 0.95 & 10 \\
Behavioral & 0.87 & 7 \\
Consequential & 0.61 & 7 \\
Ritual & 0.66 & 3 \\
\hline
\end{tabular}

In table 1 the obtained alpha coefficient for each of the dimensions of the independent variables can be seen. Totally the obtained alpha coefficient shows the reliability of the items, the religiosity alpha is 0.87 which is acceptable.

Table 2. Distribution Based on Parents' Education

\begin{tabular}{llll}
\hline Education & Statistics & Mother & Father \\
\hline Illiterate & Frequency & 112 & 62 \\
& Percent & 34.5 & 19.1 \\
Elementary & Frequency & 85 & 70 \\
& Percent & 26.5 & 21.5 \\
Guidance Degree & Frequency & 30 & 40 \\
& Percent & 9.2 & 12.3 \\
Diploma & Frequency & 53 & 52 \\
& Percent & 16.3 & 16 \\
A.A & Frequency & 18 & 30 \\
& Percent & 5.5 & 9.2 \\
B.A & Frequency & 25 & 60 \\
& Percent & 7.7 & 18.5 \\
Higher than B.A & Frequency & 2 & 11 \\
& Percent & 0.6 & 3.4 \\
Total & Frequency & 325 & 325 \\
& Percent & 100 & 100 \\
\hline
\end{tabular}

According to Table 2 concerning fathers' education the highest frequency is 70 , equal to 21.5 percent of fathers with elementary education, 19.1 were illiterate, 18.5 had B.A, 16\% had diploma, 12.3 had guidance degree, 9.2 had A.A and 3.4 had degrees higher than B.A. according to the table, 34.5, that is 112 of the mothers were illiterate, 26.2, that is 85 had elementary education, 16.3, that is 53 had diploma, 9.2 (30) had guidance degree, 7.7 (25) had B.A, 5.5 (18) had A.A and 0.6 (2) had degrees higher than B.A

Table 3. Cronbach's Alpha Test on Lifestyle

\begin{tabular}{ccc}
\hline Variable & Cronbach's alpha coefficient & Number of Items \\
\hline Lifestyle & 0.79 & 25 \\
\hline
\end{tabular}

Table 3 Cronbach's alpha coefficient for the dependent variable of lifestyle whose value is 0.79 shows that the reliability of the items is very high.

Table 4. Pearson Correlation Coefficient Test between Age and Lifestyle

\begin{tabular}{ccc}
\hline Variable & $\begin{array}{c}\text { The correlation } \\
\text { coefficient } \mathbf{r}\end{array}$ & Significance Level (sig) \\
\hline Age and Lifestyle & 0.02 & 0.714 \\
\hline
\end{tabular}

Hypothesis 5: there is a significant relationship between age and lifestyle. According to Table 4, the obtained between age and lifestyle is 0.02 and is not meaningful, therefore the above hypothesis is rejected. In other words, there is no significant relationship between age and lifestyle. 
Table 5. The One-Way Variance Analysis of among Ethnicity, Parents' Education and Lifestyle

\begin{tabular}{lcc}
\hline Variable & F & Significance Level (sig) \\
\hline Ethnicity and Lifestyle & 1.548 & 0.188 \\
Fathers' Education and Lifestyle & 2.619 & 0.017 \\
Mothers' Education and Lifestyle & 2.256 & 0.038 \\
\hline
\end{tabular}

Hypothesis 6: There is a significant relationship between ethnicity and lifestyle. According to table 5 and the test, $\mathrm{F}$ is 1.548 which is not significant at the level of 0.188 and the level of significance is higher than 0.05 , therefore there is no meaningful relationship between ethnicity and lifestyle so the hypothesis is not approved with 0.95 of certainty.

Hypothesis 7: there is a significant relationship between parents' education and lifestyle. According to table 3-5 and the test, the value of $\mathrm{F}$ for fathers and mothers is 2.619 and 2.256 respectively and each is significant at the levels of 0.017 and 0.038 respectively and the level of significance is less than 0.05 , therefore there is no relationship between parents' education and lifestyle so the hypothesis is not approved with 0.95 of certainty.

Table 6. Pearson Correlation Coefficient Test between Dimensions of Religiosity and Lifestyle

\begin{tabular}{ccc}
\hline Variable & $\begin{array}{c}\text { Correlation } \\
\text { coefficient R }\end{array}$ & Significance Level \\
\hline $\begin{array}{c}\text { The Belief Dimension of Religiosity and Lifestyle } \\
\text { The Behavioral Dimension of Religiosity and } \\
\text { Lifestyle }\end{array}$ & -0.207 & 0.000 \\
$\begin{array}{c}\text { Lifestyle } \\
\text { The Consequential Dimension of Religiosity and }\end{array}$ & -0.012 & 0.827 \\
The Ritual Dimension of Religiosity and Lifestyle & 0.116 & 0.000 \\
\hline
\end{tabular}

According to table 6 , the obtained $r$ between belief dimension and lifestyle is -0.207 which is significant at the level of 0.00 because sig is less than 0.01 so the hypothesis is approved. But the negative mark of Pearson coefficient value shows that there is a negative and inverse relationship between these two variables.

According to the table, the obtained $r$ between the behavioral dimension of religiosity and lifestyle is 0.021 , and is not significant at the level of 0.827 because sig is less than 0.021 , therefore the hypothesis is not approved. In other words, there is no significant relationship between the behavioral dimension and lifestyle.

According to the table, the obtained $r$ between consequences of religiosity and lifestyle is 0.312 which is significant at the level of 0.00 , because sig is less than 0.01 , so the hypothesis is approved.

According to the table, the obtained $\mathrm{r}$ between belief dimension of religiosity and lifestyle is 0.116 and is significant at the level of 0.036 , because sig is less than 0.05 so the above hypothesis is approved and it shows that there is a significant relationship between the ritual dimensions of religiosity and lifestyle.

Table 7. Pearson Correlation Coefficient Test between Religiosity and Lifestyle

\begin{tabular}{ccc}
\hline Variable & Correlation Coefficient R & Significance Level (sig) \\
\hline Religiosity and Lifestyle & -0.023 & 0.05 \\
\hline
\end{tabular}

Hypothesis 8: There is a significant relationship between religiosity and lifestyle. According to table 7 the obtained $r$ between religiosity and lifestyle is -0.023 and because sig is less than 0.05 so the above hypothesis is approved. In other words, there is a significant relationship between religiosity and lifestyle.

Table 8. Regression Equation and its Statistics

\begin{tabular}{cccccccc}
\hline & $\mathrm{R}$ & $\begin{array}{c}\text { Determination } \\
\text { Coefficient }\end{array}$ & $\begin{array}{c}\text { Standardized } \\
\text { determination } \\
\text { coefficient }\end{array}$ & Beta & F & T & Sig \\
\hline Religiosity & 0.349 & 0.121 & 0.116 & - & 22.267 & - & 0.000 \\
Consequential & - & - & - & 0.331 & - & 6.292 & 0.000 \\
Ritual & - & - & - & 0.157 & - & 2.989 & 0.003 \\
\hline
\end{tabular}


According to table 7 and based on the final regression model of the study it can be said that through step-by-step method it became clear that two variables (the consequential and ritual dimensions) respectively explained lifestyle. The intensity of the relationship of these factors with the dependent variable $\mathrm{R}$ was 0.34 which shows an average relationship among the studied variables and the dependent variable. Also based on adjusted determination coefficient it can be said that 11.6 of the lifestyle changes can be explained by these two variables. According to ANOVA test it can be said that the above model has been significant in the regression equation for studying the effect of the two mentioned variables on lifestyle, and its significance coefficient has been 0.000 with the value of $\mathrm{F}=$ 22.26 .

In this test and according to Table 8 , it can be seen that among the dimensions of religiosity, two consequential and ritual dimensions were more effective on lifestyle and the two belief and behavioral dimensions had not a significant level and have been put out of the model. The first dimension of religiosity which had a maximum effect on lifestyle was the consequential dimension. In fact it can be said that per each unit of change in the standard deviation of religiosity consequential dimension, 0.33 of change occurred in the lifestyle. The second effective variable is the ritual dimension; the value of beta shows that per each unit of change in the standard deviation of ritual dimension, 0.15 of change occurs in lifestyle.

\section{Conclusion}

From the very far past up to now human life has undergone many changes. In the modern era the changes are surprising and complicating. These complexities can be better seen in the light of relationships and choices ahead in the way of human life (Berger and et al, 2008:93). The present work has studied the effect of different lifestyles on the religiosity of male dormitory students at Shiraz University. To explain this relationship Gluck and Stark's theory about religiosity and Bourdieu's theory about lifestyle were taken as the theoretical framework.

Based on the theoretical framework of the study eight hypotheses were proposed. To study this relationship 325 male students were chosen in several stages and randomly, through survey method and by means of questionnaire, the necessary data was gathered about lifestyle and religiosity. Among the dimensions of religiosity (belief, consequential, behavioral and ritual) except for the behavioral dimension, there was a significant relationship between the other dimensions of religiosity and lifestyle, and among the contextual variables there was just a significant relationship between parents' education and lifestyle.

Lifestyle has been explained up to 11.6 by religiosity. Based on this, the religious capital, which is the main capital in this study, shows a significant relationship with most components of lifestyle, in a way that the lifestyle features of a religious person can be distinguished from those of a less religious one. In fact it can be said that the outcome of this study, in a way, approved its own ancestors and is in line with them. The findings of the study show that there is a significant relationship between consequential, ritual, belief dimensions of religiosity and lifestyle.

These findings of the study are in line with those of Karami Ghahi and Zadsar (2013), Khajenoori et. al. (2012), Zolfaghari and Nosrati (2012), Salmoirago-Blotcher et. al. (2011), and Gillum and Holt (2010).

Since that Iranian are committed to traditions and religious teachings (especially the belief and affective dimensions) and are also exposed to modernity, are always in transition from this stage. The phenomenon of the conflict between tradition and modernity, and religion and modernity is not just limited to Iranian society, almost all developing countries are in such a struggle. Because technology and the way of using it in developing countries has not been inherent, so the youth, especially students are immediately attracted and affected by it, and in the conflict between tradition and modernity they turn a deaf ear to tradition or are less likely to follow it.

Since the relationship between the youth and other cultures cannot be eradicated, and the spread of technology cannot be avoided, the youth can be warned against the abuses of technology through awareness. This awareness and solutions are of religious scholars' responsibilities.

\section{References}

Aryan, Kh. (1999). Investigating the Relationship between Religiosity and Psychic Health, PhD Thesis. Tehran: Allameh Tabatabaei University.

Berger, P. L., Berger, B., \& Kellner H. (1974). The homeless mind. New York: Random House.

Ellison, C. G., Roalson, L. A., Guillory, J. M., Flannelly, K. J., \& Marcum, J. P. (2010). Religious resources, spiritual struggles, and mental health in a nationwide sample of PCUSA clergy. Pastoral psychology, 59(3), 
287-304.

Giddens, A. (1991). Modernity and self-identity: Self and society in the late modern age. Stanford University Press.

Gillum R. F., \& Cheryl L. H. (2010). Associations between Religious Involvement and Behavioral Risk Factors for HIV/AIDS in American Women and Men In a National Health Survey. The Society of Behavioral Medicine, 40, 284-293. http://dx.doi.org/10.1007/s12160-010-9218-0

Iman, M. T., \& Keizaghan, T. (2002). Investigating the Factors that Affect Social Identity of Women. Journal of Human Sciences, 12, 79-107.

Karami Ghahi, M. T., \& Zadsar, Z. (2013). Investigating the Relationship between Religiosity and Lifestyle. Women in Culture and Art Journal, 1, 85-101.

Khajenoori, B., Mosavat, E., \& Riahi, Z. (2012). The Relationship between Lifestyle and Religiosity, Case Study: Shiraz Youths. The Journal of Social Sciences, 7(20), 103-130.

Rafatjah, M., \& Shakoori, A. (2008). Women and Re-definition of Society's Identity. Women Quarterly, 1, 71-91.

Salmoirago-Blotcher, E., Fitchett, G., Ockene, J.K., Schnall, E., Crawford, S., Granek, I., Manson, J., Ockene, I., O'Sullivan, M.J., Powell, L., \& Rapp, S. (2011). Religion and healthy lifestyle behaviors among postmenopausal women: the women's health initiative. Journal of behavioral medicine, 34(5), 360-371. http://dx.doi.org/10.1007/s11089-009-0239-1

Serajzadeh, H. (2005). Religious Attitudes and Behaviors of Tehran's Youths. Namaye Pajoohesh Journal, 7, 105-109.

Storey, John, ed. (2006). Cultural theory and popular culture: A reader. University of Georgia Press.

Willaims, J. P. (1995). Sociologie des Religions. Paris: Presses Universitaires de France.

Zolfaghari, A., \& Nosrati, S. (2012). The Effect of Religiosity on Youths' Lifestyle. Social Research Journal, 14. 